\title{
Temperature-dependent growth of pulsed-laser-deposited bismuth thin films on glass substrates
}

\author{
Keng-Shuo Wu, Ming-Yau Chern * \\ Department of Physics, National Taiwan University, Taipei, 10617, Taiwan
}

Received 5 July 2006; received in revised form 23 March 2007; accepted 14 June 2007

Available online 22 June 2007

\begin{abstract}
Bismuth thin films were grown by pulsed-laser deposition on glass substrates with the substrate temperature from $-40{ }^{\circ} \mathrm{C}$ to $200{ }^{\circ} \mathrm{C}$. The structure of the films was characterized by X-ray diffraction. The surface morphology was studied by atomic force microscopy and X-ray reflectivity. The electrical properties of the films were probed by Hall and van der Pauw measurements. We observed changes in the orientation, grain size and roughness of the bismuth films as a function of the substrate temperature. In particular, at $-30{ }^{\circ} \mathrm{C}$, the surface roughness was drastically reduced, leading to very smooth bismuth films with highly (111)-preferred orientation. Furthermore, the preferred orientation disappeared at around $-40{ }^{\circ} \mathrm{C}$.
\end{abstract}

(C) 2007 Elsevier B.V. All rights reserved.

Keywords: Bismuth thin films; Pulsed-laser deposition; Preferred orientation; Roughness; Electrical properties

\section{Introduction}

Bismuth films have many interesting properties. As indicated in the reports, amorphous bismuth film is a superconductor below $6 \mathrm{~K}$, while rhombohedral $\mathrm{Bi}$ is not superconducting [1-3]. Bismuth thin films also exhibit giant third-order optical nonlinearity [4]. The physical properties of crystalline Bi vary with their crystallographic orientations due to the highly anisotropic Fermi surface. In order to study the structure-dependent and orientation-dependent properties of $\mathrm{Bi}$ thin films, a structureand orientation-controlled growth of the films is necessary.

As reported in the literature, the structure of $\mathrm{Bi}$ films is immensely influenced by the substrates. Grown on Si substrates with different orientations, polycrystalline Bi films could exhibit different preferred orientations upon annealing at $267^{\circ} \mathrm{C}$ for $8 \mathrm{~h}$ [5]. To elevate the film quality, lattice matched substrates, e.g. $\mathrm{CdTe}$ and $\mathrm{BaF}_{2}$, are applied to the epitaxial growth of high quality single crystalline $\mathrm{Bi}$ films [6-8]. It is found that $\mathrm{Bi}$ deposited on the $\mathrm{CdTe}(111) \mathrm{A}$ (Cd-terminated) surface grows in three-dimensional islanding mode, while Bi deposited on the CdTe(111)B (Te-terminated) grows layer by layer [6]. Even

\footnotetext{
* Corresponding author.

E-mail address: mychern@ccms.ntu.edu.tw (M.-Y. Chern).
}

when the bismuth films are grown on single-crystal $\mathrm{BaF}_{2}$, the initial grown layers can be amorphous [8,9]. Besides the orientation and lattice match, substrate temperature is also a key parameter, especially when the Bi films are grown on amorphous substrates. For example, when the films are grown on amorphous $\mathrm{Al}_{2} \mathrm{O}_{3}$ substrates at liquid helium temperature, the structure of the initial few atomic layers is amorphous [10]. If the films are grown on glass or graphite at room temperature, polycrystalline structure is observed, while the crystal plane parallel to the substrate surface is preferred in the (111) orientation [11-17]. When the substrate temperature is higher than $100^{\circ} \mathrm{C}$, the structure of the films is polycrystalline with random orientation [13-18].

Pulsed-laser deposition (PLD) is a thin-film-growth technique known for the capability to produce high-quality oxide films, such as high-temperature superconductors, ferroelectrics and $\mathrm{ZnO}$, etc. [20-22]. Recently, bismuth thin films grown by PLD have also been studied with the range of the substrate temperature varied from room temperature to $271{ }^{\circ} \mathrm{C}$ [17-19]. However, the growth by PLD below room temperature is less studied in detail.

In this paper, we report the temperature-dependent growth of pulsed-laser-deposited Bi films from $-40{ }^{\circ} \mathrm{C}$ to $200{ }^{\circ} \mathrm{C}$. Both the structure and surface morphology of the films were studied. 
We observed that the roughness of the film was drastically reduced by decreasing the substrate temperature. Most importantly, we found that $-30{ }^{\circ} \mathrm{C}$ was the optimized temperature for the growth of very smooth bismuth thin films with highly (111)-preferred orientation, which is very useful for applying Bi thin films to data storage disks. For example, the $\mathrm{MnBi}$ film is a promising candidate for the high-recordingdensity magneto-optical disk [14]. However, as reported by Nakada et al., the surface roughness of Bi layers is one of the main causes of the disk noise. Furthermore, the (111)-preferred orientation of the Bi layer reduces the annealing temperature required to grow the uniform $\mathrm{MnBi}$ films. Therefore, smooth bismuth thin films with highly (111)-preferred orientation are very helpful for the application in magneto-optical disks.

The electrical properties of bismuth thin films are also interesting. Although bulk bismuth crystals exhibit n-type conductivity at room temperature, bismuth thin films reported in the literature almost exhibit p-type conductivity at room temperature [23]. Furthermore, bismuth thin films are the most favorable material for exploring the size effect on the electrical properties [24]. In the present work, the electrical properties of bismuth thin films grown below $50{ }^{\circ} \mathrm{C}$ were studied by Hall and van der Pauw measurements. All the films exhibited p-type conductivity at room temperature. The orientation-dependent behaviors in the resistivity, Hall coefficient, and mobility of the films as well as the ordinary size effect were observed.

\section{Experimental details}

Bismuth thin films were grown by PLD on glass substrates in vacuum. Prior to the film deposition, the glass substrates (Corning 7059) have been annealed at $600{ }^{\circ} \mathrm{C}$ for $24 \mathrm{~h}$ and washed under an ultrasonic bath of alcohol. During the process of PLD, a bismuth (99.999\%) target was ablated by a pulsed $\mathrm{KrF}$ excimer laser (248 nm, $23 \mathrm{~ns}, 1 \mathrm{~Hz}, 200$ pulses) with an energy of $125 \mathrm{~mJ}$ per pulse and a fluence of $4 \mathrm{~J} / \mathrm{cm}^{2}$ (We kept the laser energy low enough not to generate undesired particulates or droplets commonly seen in the PLD process.). The incidence angle of the excimer laser was $30^{\circ}$ to the normal of the Bi target. The bismuth vaporized into a plume after the absorption of the laser energy, and then condensed on the glass substrate facing the target at a distance of $45 \mathrm{~mm}$. The temperature of the substrate could be set from $-40{ }^{\circ} \mathrm{C}$ to $200^{\circ} \mathrm{C}$ and held during the deposition process. The deposition was performed in a chamber pumped by a turbo molecular pump to yield a base pressure of $6.7 \times 10^{-6} \mathrm{~Pa}$.

Bragg-Brentano X-ray diffraction $(\theta-2 \theta \mathrm{XRD})$ and glancing angle X-ray diffraction (GAXRD) with the $\mathrm{Cu} \mathrm{K}_{\alpha}$ radiation were used to characterize the structure of the film $[25,26]$. The incidence angle and the diffraction angle are scanned simultaneously in $\theta-2 \theta$ XRD, whereas in GAXRD only the diffraction angle is scanned, while keeping the incidence angle fixed at a small angle. The $\theta-2 \theta \mathrm{XRD}$ is used to analyze the crystal planes parallel to the substrate surface. However, when the thickness of the thin films is much smaller than the penetration depth of the X-ray, or when the grain of the samples is nano-sized, the intensity of the diffracted X-ray might become too weak to be detected. In such cases,
GAXRD is used to obtain complementary crystallographic information from the sample. In the GAXRD, the incidence angle is held at $0.6^{\circ}$ so that the X-ray traveling length in the films is much longer than that in the $\theta-2 \theta \mathrm{XRD}$, resulting in more diffracted X-ray energy by the films. In addition, due to its asymmetric diffraction geometry, the crystal planes not parallel to the substrate surface can be accessed by GAXRD. The surface morphology was probed by atomic force microscopy (AFM) in semi-contact mode. The thickness and average roughness of the films were measured by X-ray reflectivity (XRR) [27-29]. In $\mathrm{XRR}$, the interference fringes and intensities of the X-ray, reflected from the air-film and film-substrate interfaces, are used to measure the thickness and the root-mean-square (rms) roughness, respectively. By fitting the reflectivity curves, the thickness and roughness of films are obtained. In order to determine

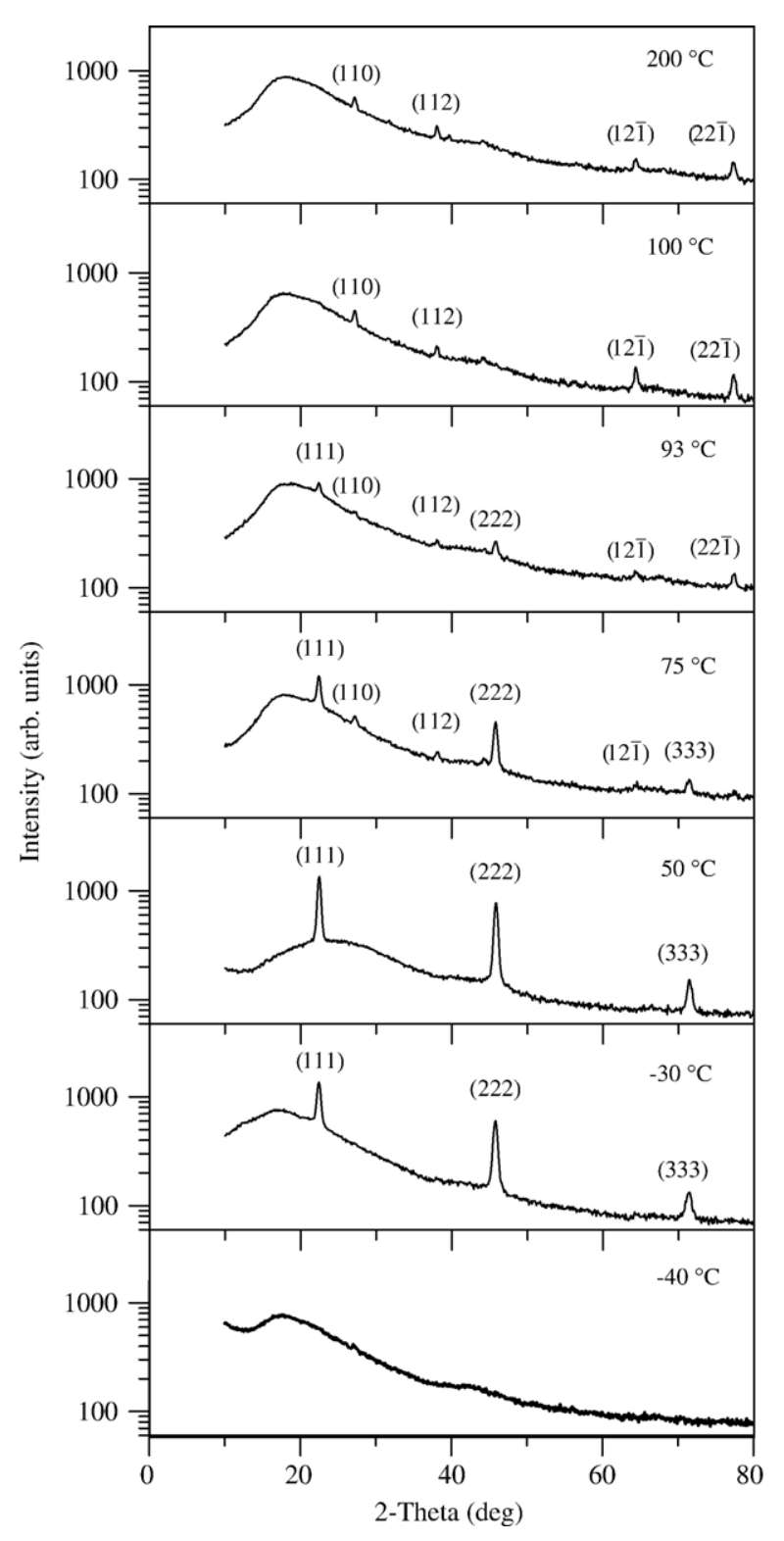

Fig. 1. $\theta-2 \theta$ XRD patterns of bismuth thin films grown at different temperatures. The indices are referred to the rhombohedral system. 


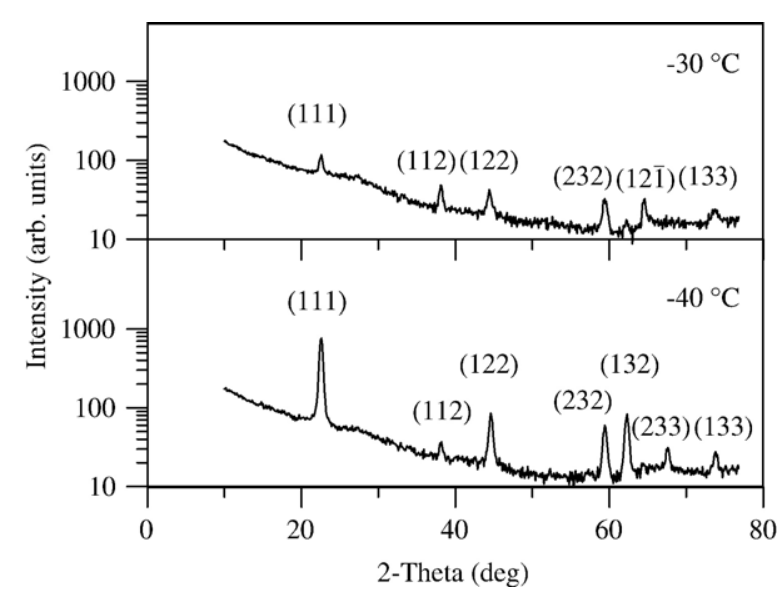

Fig. 2. GAXRD patterns of bismuth thin films grown at $-30{ }^{\circ} \mathrm{C}$ and $-40{ }^{\circ} \mathrm{C}$.

precisely the interference fringes, a highly parallel beam is very useful. The beam generated from the X-ray source is set to pass through a parabolic Göbel mirror and two monochromating channel-cut crystals, leading to the divergence of the beam smaller than $15^{\prime \prime}$. Under such experimental conditions, a 3\% change in thickness is easily detectable with XRR.

To study the electrical properties of Bi films, Hall and van der Pauw measurements were performed at room temperature [30]. Four corners of the square Bi film were conducted by small drops of conductive silver paint. A magnetic field of $0.4 \mathrm{~T}$ was applied perpendicularly to the film surface to measure the Hall voltage. For van der Pauw measurement, the current was reversed to eliminate errors due to thermal offsets. For Hall measurement, both the current and the magnetic field were also reversed to average out errors.

\section{Results and discussion}

\subsection{X-ray diffraction analysis}

The $\theta-2 \theta$ XRD patterns of the Bi films grown at various temperatures are shown in Fig. 1. For substrate temperatures ranging from $200{ }^{\circ} \mathrm{C}$ to $100{ }^{\circ} \mathrm{C}$, peaks belonging to different crystal planes coexist in the patterns, i.e. (110), (112), (12 $\overline{1})$ and (22) $\overline{1}$ ), and their relative intensities correspond to those of bulk $\mathrm{Bi}$, indicating that the films are polycrystalline with random orientations. From $93{ }^{\circ} \mathrm{C}$ to $75^{\circ} \mathrm{C}$, the intensity of the peaks mentioned above gradually becomes smaller while the peaks belonging to the (111) orientation, i.e. (111), (222), (333), start to grow. Between $50{ }^{\circ} \mathrm{C}$ and $-30{ }^{\circ} \mathrm{C}$, only $\{111\}$ peaks exist in the $\theta-2 \theta$ XRD patterns so the films could be either highly preferred at (111) orientation or single crystalline. At $-40{ }^{\circ} \mathrm{C}$, no obvious peaks are seen, where the structure could be amorphous or nanocrystalline. In order to elucidate the film structure, GAXRD measurements of the films grown at $-30{ }^{\circ} \mathrm{C}$ and $-40{ }^{\circ} \mathrm{C}$ were performed. As shown in the Fig. 2, the peaks of different crystal orientations previously unobserved appear in the GAXRD patterns. It means that both the films are polycrystalline. Considering both the $\theta-2 \theta$ XRD and GAXRD patterns, one can conclude that the bismuth thin film is highly preferred in the (111) orientation between $50{ }^{\circ} \mathrm{C}$ and $-30{ }^{\circ} \mathrm{C}$ but it is not single crystalline. At $-40^{\circ} \mathrm{C}$, the (111)-preferred orientation vanishes,

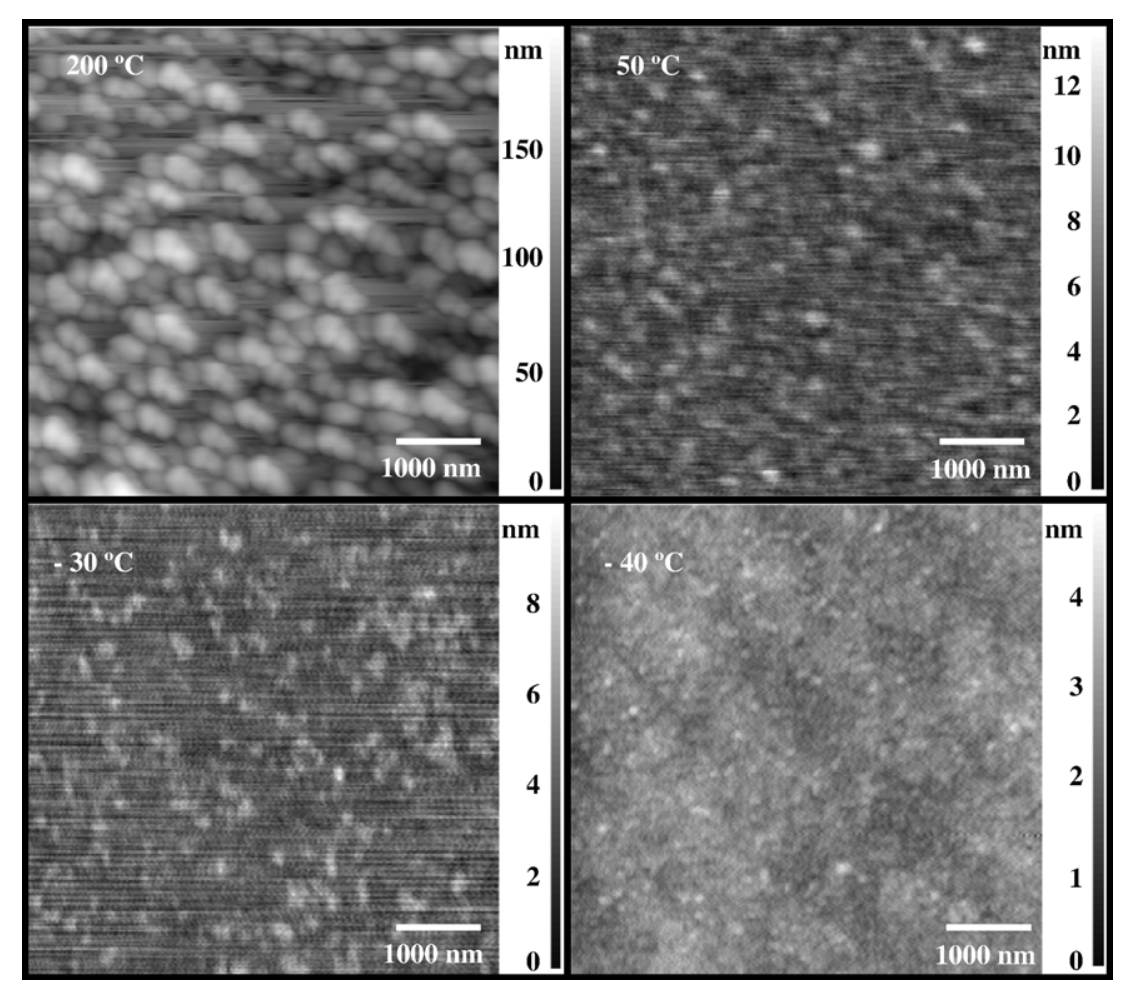

Fig. 3. AFM images of bismuth thin films grown at different temperatures. 
yet the bismuth thin films are not amorphous but composed of nano-crystals. For the films grown above room temperature, the results of our XRD measurements agree well with those in the literature [11-18].

\subsection{Atomic force microscopy}

The surface morphology of the films was mapped by AFM, as shown in Fig. 3. For the film grown at $200{ }^{\circ} \mathrm{C}$, large roundshaped grains, with an average diameter $500 \mathrm{~nm}$, are observed. The variation in height is about $50 \mathrm{~nm}$, and the rms roughness is about $30 \mathrm{~nm}$. When the substrate temperature is lowered to $50{ }^{\circ} \mathrm{C}$, the film is made of closely-packed grains with diameter smaller than $250 \mathrm{~nm}$. The variation in height is smaller than $5 \mathrm{~nm}$ and the rms roughness is decreased to about $1.35 \mathrm{~nm}$. For the substrate temperature lowered to $-40{ }^{\circ} \mathrm{C}$, the grains are even smaller and the film surface is very smooth. Here, the local fluctuation in height is well below $1 \mathrm{~nm}$ and the roughness is reduced to about $0.75 \mathrm{~nm}$. These results are similar to those reported by Dauscher et al. [17]. They observed that Bi films grown at $185^{\circ} \mathrm{C}$ by PLD are rough, while the films grown at room temperature exhibit very smooth surfaces.

As reported by Zayed and Elsayed-Ali [16], thermal bismuth vapor could condense into liquid or solid phases depending on the pressure and the substrate temperature. They observed, by in situ reflection high-energy electron diffraction, $140{ }^{\circ} \mathrm{C} \pm 5^{\circ} \mathrm{C}$ to be the limit in temperature above which the condensation of liquid phase starts to occur; whereas, solid phase is observed below this limit. Considering the high kinetic energy of the species in the PLD plasma, this temperature limit is expected to be lower. Therefore, based on the results from the X-ray diffraction and AFM measurements, we suggest that the growth of the films at temperatures higher than about $100{ }^{\circ} \mathrm{C}$ begins with the liquid phase condensed from the bismuth plasma.

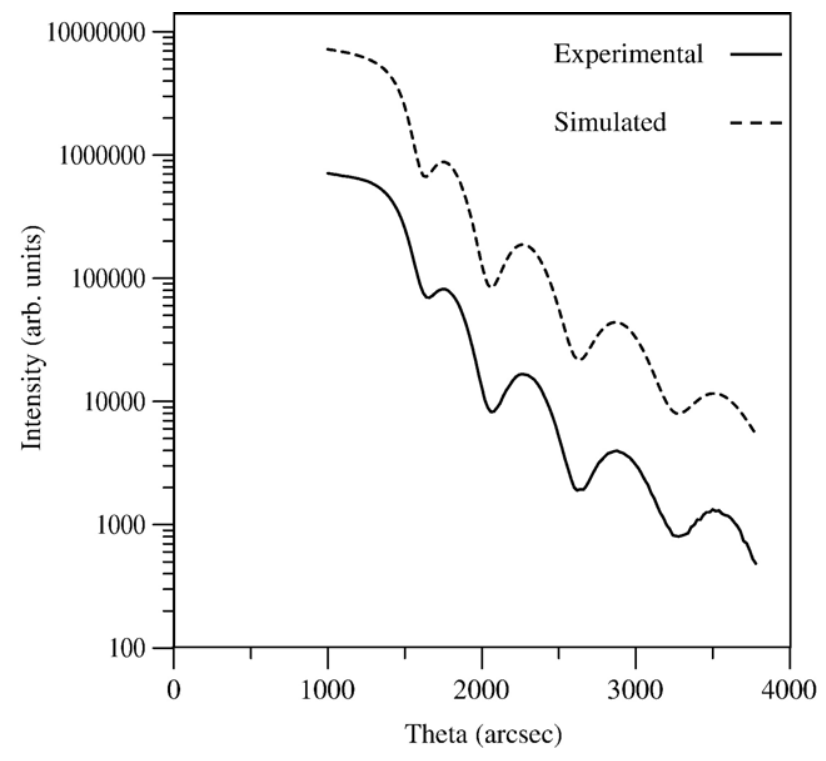

Fig. 4. Experimental and simulated XRR profiles of Bi film grown at $-30{ }^{\circ} \mathrm{C}$. The simulated curve is shifted up by 1 order of magnitude for comparison.
Table 1

The thickness and roughness of films grown at different substrate temperatures

\begin{tabular}{|c|c|c|c|}
\hline \multirow[t]{2}{*}{$\begin{array}{l}\text { Temperature } \\
\left({ }^{\circ} \mathrm{C}\right)\end{array}$} & $\begin{array}{l}\text { Thickness } \\
(\mathrm{nm})\end{array}$ & $\begin{array}{l}\text { Roughness } \\
(\mathrm{nm})\end{array}$ & $\begin{array}{l}\text { Roughness } \\
(\mathrm{nm})\end{array}$ \\
\hline & $(\mathrm{XRR})^{\mathrm{a}}$ & $(\mathrm{XRR})^{\mathrm{a}}$ & $(\mathrm{AFM})^{\mathrm{a}}$ \\
\hline 200 & & & 30.00 \\
\hline 50 & 27 & 1.33 & 1.35 \\
\hline 25 & 27 & 1.22 & 1.20 \\
\hline-10 & 28 & 1.11 & 1.10 \\
\hline-30 & 22 & 0.68 & 1.05 \\
\hline-40 & 28 & 0.64 & 0.75 \\
\hline
\end{tabular}

\#All films are grown by PLD for 200 laser pulses.

${ }^{a}$ Measurement method.

Then, the liquid bismuth forms individual droplets due to the surface tension and the cohesive force, resulting in roundshaped grains in the film upon solidification. Within the droplets, the crystallization begins without any directional restriction, leading to a randomly oriented polycrystalline structure. At lower temperatures, below about $100^{\circ} \mathrm{C}$, the bismuth vapor condenses directly into the solid phase without going through the liquid phase. As the substrate temperature is lowered, the surface diffusion of the $\mathrm{Bi}$ adatoms is also reduced, resulting in smaller grains uniformly packed in the film. Under the interference of the substrate surface, for the even lower temperatures, from $50{ }^{\circ} \mathrm{C}$ to $-30{ }^{\circ} \mathrm{C}$, the growth in [111] is suggested to be much more rapid than in other directions, leading to the (111)-preferred orientation.

\subsection{X-ray reflectivity}

As a supplementary tool to AFM to obtain the rms roughness and thickness of the films, XRR was performed for the bismuth films grown below $50{ }^{\circ} \mathrm{C}$ (The film grown at $200{ }^{\circ} \mathrm{C}$ was too rough to be analyzed properly by XRR.). By fitting the reflectivity curves, as illustrated in Fig. 4, the thickness and roughness of the films were obtained and are listed in Table 1, which also includes the data measured by AFM for comparison. It is found that the roughness measured by XRR is decreased at lower substrate temperatures, which is in agreement with the results from AFM. The thickness of the Bi films is about $22-28 \mathrm{~nm}$ for 200 laser pulses, so the growth rate is $0.11-0.14 \mathrm{~nm}$ per pulse.

Table 2

The electrical properties of films grown at different substrate temperatures ${ }^{\#}$

\begin{tabular}{|c|c|c|c|}
\hline Temperature & Resistivity & Hall coefficient & Mobility \\
\hline$\left({ }^{\circ} \mathrm{C}\right)$ & $\overline{\left(10^{-4} \Omega \mathrm{cm}\right)}$ & $\overline{\left(10^{-2} \mathrm{~cm}^{3} / \mathrm{C}\right)}$ & $\left(10^{2} \mathrm{~cm}^{2} /\right.$ volt $\left.\mathrm{s}\right)$ \\
\hline 50 & 5.70 & 8.90 & 1.56 \\
\hline 25 & 8.66 & 11.00 & 1.27 \\
\hline-10 & 6.63 & 7.73 & 1.17 \\
\hline-30 & 10.40 & 6.01 & 0.58 \\
\hline-40 & 5.19 & 23.76 & 4.58 \\
\hline
\end{tabular}

${ }^{\#}$ All films exhibit p-type conductivity. 


\subsection{Electrical properties}

Measurements, including electrical resistivity, Hall coefficient, and Hall mobility, were performed to study the electrical properties of bismuth films grown at different temperatures. The film grown at $200{ }^{\circ} \mathrm{C}$ is non-conductive, indicating that the round-shaped grains in the film might not be interconnected. Comparing with bulk $\mathrm{Bi}$, the resistivity of the $\mathrm{Bi}$ films grown below $50{ }^{\circ} \mathrm{C}$ is increased (see Table 2), which could be attributed to the ordinary size effect. As indicated by Hoffman et al. [24], due to the additional scattering at the sample surface, ordinary size effect (increase in resistivity) is seen when the mean free path of the charge-carrier (about $0.6 \mu \mathrm{m}$ for Bi at room temperature [24]) is comparable with or greater than the sample thickness (about $25 \mathrm{~nm}$ ). Comparing our results with those of the literature for similar film thickness, the electrical resistivity is of the same order but higher than most of the previous investigations [23,31-35]. Boffoué et al. [35] also observed the higher resistivity of bismuth films grown by PLD, and attributed this phenomenon to the low deposition temperature and the absence of post annealing. The Hall coefficient at room temperature is positive for all our bismuth films. This is consistent with most of the previous measurements for similar film thickness $[23,32]$, yet contrary to the result by Boffoue et al. They reported that the Hall coefficient at room temperature is negative when the film thickness is smaller than $50 \mathrm{~nm}$. Among the films grown below $50{ }^{\circ} \mathrm{C}$, the film deposited at $-30{ }^{\circ} \mathrm{C}$ exhibits the highest resistivity, but the lowest Hall coefficient and mobility. This peculiar electrical behavior of the film might be attributed to its smaller thickness. On the other hand, the film deposited at $-40{ }^{\circ} \mathrm{C}$ is most interesting for its lowest resistivity, but highest Hall coefficient and mobility, even though the thickness is similar to the films grown between $-10{ }^{\circ} \mathrm{C}$ and $50{ }^{\circ} \mathrm{C}$. From X-ray diffraction, the structure of the film deposited at $-40{ }^{\circ} \mathrm{C}$ is clearly different from the other films grown at higher temperatures. It is well known that the band structure of $\mathrm{Bi}$ is highly anisotropic so the electrical properties are expected to be anisotropic too. We believe the drastic changes in the electrical properties of the film are due to the change in the crystalline orientation of the grains.

\section{Conclusions}

Bismuth thin films with a variety of structures have been grown by PLD on glass substrates. The substrate temperature is the key parameter responsible for the variation. When the temperature is above $100{ }^{\circ} \mathrm{C}$, random-oriented polycrystalline structure is observed. Between $93{ }^{\circ} \mathrm{C}$ and $-30{ }^{\circ} \mathrm{C}$, the (111)preferred orientation is obtained. At $-40^{\circ} \mathrm{C}$, the (111)-preferred orientation vanishes and the film is polycrystalline. As the temperature decreases, both the grain size and the film roughness are largely decreased. It is found that the optimized temperature for the growth of very smooth bismuth thin films with highly (111)-preferred orientation is $-30{ }^{\circ} \mathrm{C}$. The results suggest that at higher temperature, the films grow from the liquid phase, leading to the formation of large round-shaped grains, while at lower temperature, the films tend to grow directly from the gas (vapor) phase, resulting in smaller and uniformly distributed grains. The electrical properties of the films are observed to be dependent on the thickness as well as crystalline orientation of the grains.

\section{Acknowledgements}

This work is supported by the National Science Council and the Ministry of Economic Affair (95-EC-17A-08-S1-0006) of the Republic of China. Ming-Yau Chern's e-mail address is mychern@ccms.ntu.edu.tw.

\section{References}

[1] T. Hamada, K. Yamakawa, F.E. Fujita, J. Phys. F. Met. Phys. 11 (1981) 657.

[2] W. Buckel, R. Hilsch, Z. Phys. 138 (1954) 109.

[3] N. Kürti, F. Simon, Proc. R. Soc. A 151 (1935) 610.

[4] D.R. Liu, K.S. Wu, M.F. Shih, M.Y. Chern, Opt. Lett. 27 (2002) 1549.

[5] J.H. Hsu, Y.S. Sun, H.X. Wang, P.C. Kuo, T.S. Hsieh, C.T. Liang, J. Magn. Magn. Mater. 272/276 (2004) 1769.

[6] S. Cho, A. DiVenere, G.K. Wong, J.B. Ketterson, J.R. Meyer, J.I. Hong, Phys. Rev., B 58 (1998) 2324.

[7] J.A. van Hulst, H.M. Jaeger, S. Radelaar, Phys. Rev., B 52 (1995) 5953.

[8] D.L. Partin, J. Heremans, D.T. Morelli, C.M. Thrush, C.H. Olk, T.A. Perry, Phys. Rev., B 38 (1988) 3818.

[9] S. Nahm, L. Salamanca-Riba, D.L. Partin, J. Heremans, J. Mater. Res. 5 (1990) 784.

[10] M.M. Rosario, Y. Liu, Phys. Rev., B 65 (2002) 094506.

[11] S. Konczak, S. Kochowski, Z. Ziolowski, Thin Solid Films 17 (1973) 199.

[12] A.A. Ramadan, A.M. El-Shabiny, N.Z. El-Sayed, Thin Solid Films 209 (1992) 32.

[13] Y. Namba, T. Mori, J. Appl. Phys. 46 (1975) 1159.

[14] M. Nakada, N. Ohshima, M. Okada, Jpn. J. Appl. Phys. 35 (1996) 714.

[15] S. Ozawa, S. Fujiwara, Thin Solid Films 37 (1976) 73.

[16] M.K. Zayed, H.E. Elsayed-Ali, Phys. Rev., B 72 (2005) 205426.

[17] A. Dauscher, M.O. Boffoué, B. Lenoir, R. Martin-Lopez, H. Scherrer, Appl. Surf. Sci. 138/139 (1999) 188.

[18] M.O. Boffoué, B. Lenoir, H. Scherrer, A. Dauscher, Thin Solid Films 322 (1998) 132.

[19] J.C.G. de Sande, T. Missana, C.N. Afonso, J. Appl. Phys. 80 (1996) 7023.

[20] D.B. Chrisey, G.K. Hubler, Pulsed Laser Deposition of Thin Films, WileyInterscience, New York, 1994.

[21] P.R. Willmott, J.R. Huber, Rev. Mod. Phys. 72 (2000) 315.

[22] M.Z. Lin, C.T. Su, H.C. Yan, M.Y. Chern, Jpn. J. Appl. Phys. 44 (2005) L995.

[23] H.T. Chu, P.N. Henriksen, J. Jing, H. Wang, X. Xu, Phys. Rev., B 19 (1992) 11233.

[24] R.A. Hoffman, D.R. Frankl, Phys. Rev., B 3 (1971) 1825.

[25] G. Lim, W. Parrish, C. Ortiz, M. Bellotto, M. Hart, J. Mater. Res. 2 (1987) 471.

[26] P.N. Gibson, M.E. Özsan, D. Lincot, P. Cowache, D. Summa, Thin Solid Films 361/362 (2000) 34.

[27] L.G. Parratt, Phys. Rev. 95 (1954) 359.

[28] D.K. Bowen, B.K. Tanner, Nanotechnology 4 (1993) 175.

[29] E. Chason, T.M. Mayer, Crit. Rev. Solid State Mater. Sci. 22 (1997) 1.

[30] P.M. Hemenger, Rev. Sci. Instrum. 44 (1973) 698.

[31] M. Inoue, H. Yagi, Y. Tamaki, Jpn. J. Appl. Phys. 12 (1973) 310.

[32] M. Inoue, Y. Tamaki, H. Yagi, J. Appl. Phys. 45 (1974) 1562.

[33] M. Subotowicz, M. Jalochowski, B. Mikolajczak, P. Mikolajczak, Phys. Status Solidi, A Appl. Res. 17 (1973) 79.

[34] F. Völklein, E. Kessler, Phys. Status Solidi, B Basic Res. 134 (1986) 351.

[35] M.O. Boffoué, B. Lenoir, A. Jacquot, H. Scherrer, A. Dauscher, M. Stölzer, J. Phys. Chem. Solids 61 (2000) 1979. 